MIA FILIĆ, mag. inf. et math. ${ }^{1}$

E-mail: filicmia@gmail.com

RENATO FILJAR, Ph.D. ${ }^{2}$

E-mail: renato.filjar@gmail.com

MARKO ŠEVROVIć, Ph.D. ${ }^{3}$

(Corresponding author)

E-mail: msevrovic@fpz.hr

1 University of Zagreb

Faculty of Electrical Engineering and Computing

Unska 3, 10000 Zagreb

2 University of Rijeka, Faculty of Engineering

Vukovarska 58, 51000 Rijeka, Croatia

${ }^{3}$ University of Zagreb

Faculty of Transport and Traffic Sciences

Vukelićeva 4, 10000 Zagreb, Croatia
Transport Engineering

Preliminary Communication

Submitted: 4 Nov. 2016

Accepted: 11 Apr. 2018

\title{
EXPRESSION OF GNSS POSITIONING ERROR IN TERMS OF DISTANCE
}

\begin{abstract}
This manuscript analyzes two methods for Global Navigation Satellite System positioning error determination for positioning performance assessment by calculation of the distance between the observed and the true positions: one using the Cartesian $3 D$ rectangular coordinate system, and the other using the spherical coordinate system, the Cartesian reference frame distance method, and haversine formula for distance calculation. The study shows unresolved issues in the utilization of position estimates in geographical reference frame for GNSS positioning performance assessment. Those lead to a recommendation for GNSS positioning performance assessment based on original WGS84-based GNSS position estimates taken from recently introduced data access from GNSS software-defined radio (SDR) receivers.
\end{abstract}

\section{KEY WORDS}

GNSS positioning error; performance assessment; distance calculation; software-defined radio (SDR);

\section{INTRODUCTION}

An assessment of a positioning method's accuracy is essential in the estimation of the performance of various position-based navigation, communication, and information systems and services [1]. Inexperienced use of different methodologies for experimental assessments frequently leads to miscalculations and inability to compare different experimental evaluations of positioning services. The problem is emphasized in the evaluation of the performance of positioning services (such as those based on the Global Navigation Satellite System, GNSS), where different accuracy assessment methodologies are frequently applied without a deeper understanding of their nature, methodology development, and simplifications used, thus undermining the value of research and providing meaningless and non-comparable results [2].

In our research, we address the problem by assessing the possible approaches to express GNSS positioning accuracy for navigation (i.e., used for applications to non-stationary objects, such as those belonging to location-based services (LBS) and intelligent transport systems (ITS) [3]), and propose a solution for a common methodology that will allow for comparison of independently conducted GNSS positioning assessments.

The manuscript is structured as follows. Section 2 discusses the problem. Section 3 outlines two common methodologies for the determination of GNSS positioning accuracy. Section 4 presents the results of performance comparison of the methodologies presented in Section 3. In Section 5, the results of Section 4 are discussed with the aim to propose the common practice in determination of GNSS positioning accuracy performance for independent studies. Section 6 concludes the manuscript and outlines the plan for near-term future research activities.

\section{PROBLEM DESCRIPTION AND RESEARCH BACKGROUND}

Continuous monitoring of GNSS service performance usually comprises the task of determining GNSS positioning error observables in navigation applications for further analysis [3,4,5]. A common cost-effective approach calls for direct collection of position error estimates from GNSS receivers, if such a feature is in operation $[1,4]$. 
Most commercially available single-frequency GNSS receivers present the results of the position estimation process based on reception of satellite ranging signals [4] in geographical coordinates, describing the estimated position with geographical longitude $(\lambda)$, geographical latitude $(\varphi)$, and height $(h)$ above the mean sea level $[1,2]$. Such an approach in expressing measurement results complies with the requirements of numerous GNSS-based applications [3]. However, expression of position estimates in that way causes a significant increase in miscalculation and misinterpretation of GNSS positioning error estimates.

In general, the GNSS positioning error is estimated by calculation of the Euclidian distance between GNSS-estimated and true positions, as expressed in

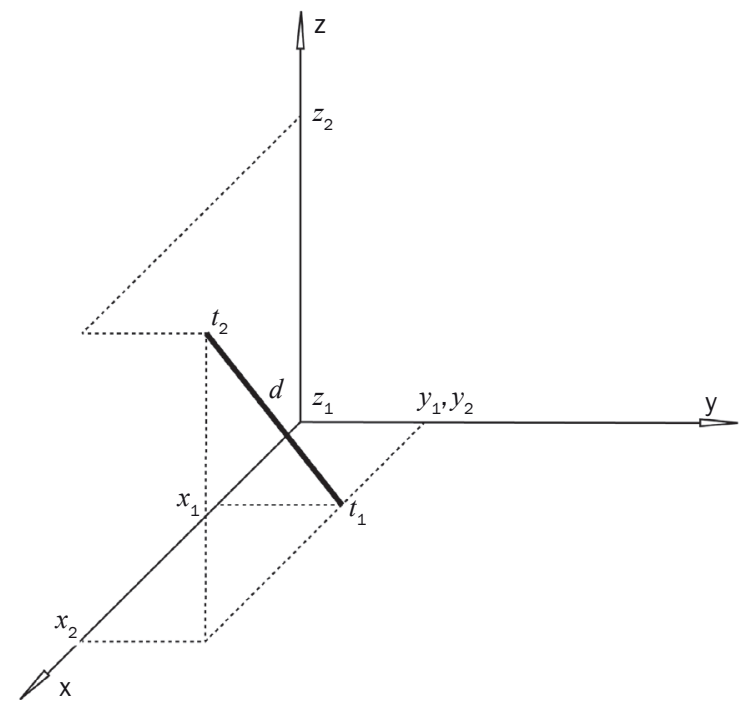

Figure 1 - Problem description: point 1 as true position, and point 2 as an estimated one

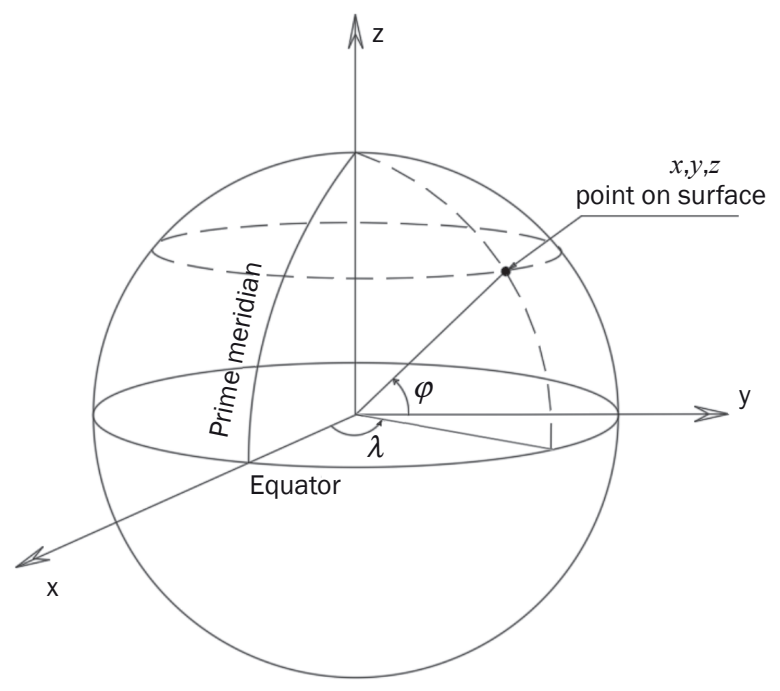

Figure 2 - Definition of position in the WGS84 reference frame
Equation 1 and depicted in Figure 1 [1,4]. Since the GNSS position estimation process usually takes place in the so-called navigation application domain and with presumed utilization of the 3D Cartesian WGS84 co-ordinate system (Figure 2), Cartesian 3D (metric) coordinates $(x, y, z)$ are used, rather than angular ones.

$d\left(T_{1}, T_{2}\right)=\sqrt{\left(x_{2}-x_{1}\right)^{2}+\left(y_{2}-y_{1}\right)^{2}+\left(z_{2}-z_{1}\right)^{2}}$

In respect of location-based telecommunication services (LBS) and intelligent transport system (ITS) services, operators and users are more concerned with planar (horizontal) positioning errors, rather than general and height-related ones [3]. This results in the nowadays increasingly common positioning error miscalculation, where researchers presume flat Earth's surface and equalize the geographic coordinates of a position (geographical latitude and geographical longitude) with the planar (horizontal) components of a position in the WGS84 Cartesian three-dimensional system $(x, y)$ in the process of horizontal GNSS error calculation. Such a practice leads inevitably to incorrect and misleading results in an increasingly frequent number of studies. The traditional design of the GNSS receiver only worsens the situation, since the GNSS position estimation process is neither transparent nor accessible by third-party applications. In recent developments, raw pseudo-range measurements from software-defined radio (SDR) GNSS receivers [6] have become accessible through dedicated application protocol interfaces (APIs) [7], thus allowing access to partial results of GNSS-based position estimation performed in the WGS84 3D Cartesian reference coordinate system [6]. Still, many researchers and engineers take the least-resistance approach in analyzing the final, rather than partial or original, results of the position estimation process.

\section{HAVERSINE-BASED GNSS POSITIONING ERROR DETERMINATION}

Assessment of GNSS position estimation error for navigation applications (including location-based services, road traffic information systems, and road-use charging) does not require the appropriate level of confidentiality [3]. The accuracy of GNSS positioning error determination derived from GNSS position estimates is to be assessed to advise the choice of a position error estimation method that will result in a significantly smaller additional estimation error than the GNSS positioning error itself [1].

We aimed at the assessment of feasibility to utilize the geographical coordinates in a GNSS positioning performance analysis, providing a suitable method was applied for correct transformation of the WGS84 position estimates into geographical ones. The haversine formula [8] was selected for the coordinate 
system transformation. In the assessment of the haversine formula approach to solving the problem, we selected the WGS84 data [2] as control.

\subsection{Transformation formulae}

A GNSS-based position estimate is usually given in the 3D Cartesian (rectangular) reference frame. A common GNSS position estimation algorithm deals with the observables and positions in the WGS84 3D Cartesian reference frame [1,2].

Commercial-grade GNSS receivers usually provide position estimates in the spatial geographical reference frame, outlining the position's latitude, longitude, and height above the Earth's mean sea level. Provision of position estimates in the spatial geographical reference frame allows for user-oriented presentation of the results of the position estimation process [1].

Transformations between the two reference frames can be conducted using transformation formulae, as described in the rest of this section.

The transformation formulae use the parameters of the Earth's ellipsoid description, as defined in Table 1 and outlined in Equations 2 and 3.

Table 1 - Earth's ellipsoid description as defined by the WGS-84 geodetic datum

\begin{tabular}{||l|c|c||}
\hline \multicolumn{1}{|c|}{ Parameter } & Name & WGS-84 value \\
\hline \hline Semi-major axis & $a$ & $6378137 \mathrm{~m}$ \\
\hline Flattening & $f$ & $1 / 298.257223563$ \\
\hline
\end{tabular}

$e^{2}=f \cdot(2-f)$

$v=\frac{a}{\sqrt{1-e^{2} \cdot \sin ^{2} \varphi}}$

Where:

e -eccentricity;

$f$-flattening;

$a$-equatorial radius (semi-major axis);

$\varphi$-geographical latitude;

$v$-Earth's radius of curvature in the prime vertical.

Equations 4-6 outline the procedure of co-ordinates transformation from the WGS84-based 3D Cartesian reference frame to the WGS84-based spatial geographical reference frame.

$\varphi=\operatorname{arctg} \frac{Z}{\sqrt{\left(X^{2}+Y^{2}\right)}} \cdot\left(1-e^{2} \frac{v}{v+h}\right)^{-1}$

$\lambda=\operatorname{arctg} \frac{Y}{X}$

$h=\frac{\sqrt{\left.X^{2}+Y^{2}\right)}}{\cos \varphi}-v$

The transformation process from the WGS84based spatial geographical reference frame to the WGS84-based 3D Cartesian reference frame is outlined in Equations 7-9.
$X=(v+h) \cdot \cos \varphi \cdot \cos \lambda$

$Y=(v+h) \cdot \cos \varphi \cdot \sin \lambda$

$Z=\left[v\left(1-e^{2}\right)+h\right] \cdot \sin \varphi$

Depending on the choice of programming environment, the angular values should be expressed in [rad] in practical deployment of the system of Equations 2-9.

\subsection{D Cartesian reference frame distance method}

Providing the real and estimated positions $\left(x_{1}, y_{1}, z_{1}\right)$ and $\left(x_{2}, y_{2}, z_{2}\right)$, respectively, are given in the 3D Cartesian reference frame, the position estimation error can be defined as the shortest distance between two points in space, as outlined by Equation 1.

Numerous authors consider Equation 1 to be the determination of the position estimation error per definition. However, as the series of position estimates provided by commercial-grade GNSS receivers, including those embedded in smartphones, utilize the geographical reference frame, the position estimates intended to serve as the input data set for positioning error calculation should be first transformed to the WGS84-based 3D Cartesian reference frame using Equations 7-9, following the application of Equation 1. This requires knowledge of the Earth's dynamics parameter values (Table 1 and Equations 1 and 2) [1,5,8]. Alternative methods may be applied using the coordinates of real and estimated positions only, as presented in Section 3.3 [8].

\subsection{Haversine formula}

Reference [8] provides a simple means for the calculation of the so-called geographical distance between two points on the ellipsoid. Approximating the shape of the Earth as an ellipsoid, the algorithm considers the geographical coordinates of positions and the radius of the sphere $\mathrm{R}$ only. The haversine formula is defined as in Equation 10:

haversine $(\Theta)=\sin ^{2}\left(\frac{\Theta}{2}\right)=\frac{1-\cos \Theta}{2}$

By defining the intermediary parameter $a$ as in Equation 11:

$a=\sin ^{2}\left(\frac{\varphi_{2}-\varphi_{1}}{2}\right)+\cos \varphi_{1} \cdot \cos \varphi_{2} \cdot \sin ^{2}\left(\frac{\lambda_{2}-\lambda 1}{2}\right)$

the great circle angular distance (in rad) can be calculated using Equation 12:

$c=\operatorname{atan} 2(\sqrt{a}, \sqrt{1-a})$

from which the geographical distance between the two points is given by Equation 13:

$d=R \cdot c$ 
The algorithm comprising Equations 10-13 can be rewritten as a single Equation 14:

$$
d=2 \cdot R \cdot \arcsin \sqrt{\sin ^{2}\left(\frac{\varphi_{2}-\varphi_{1}}{2}\right)+\cos \varphi_{1} \cdot \cos \left(\varphi_{2} \cdot \sin ^{2}\left(\frac{\lambda_{2}-\lambda_{1}}{2}\right)\right)}
$$

\section{ASSESSMENT OF THE HAVERSINE FORMULA METHOD PERFORMANCE}

We assessed the performance of the haversine formula approach by comparing the positioning error data with the data obtained using the WGS84 method. The results are presented in this section with the aim to propose a standard operation procedure for positioning error estimation in the field of navigation applications in location-based services and intelligent transport systems.

Two methods for positioning error calculations (Cartesian, Section 3.2, and haversine, Section 3.3) were used for algorithm development and were deployed in the open-source statistical programming environment for statistical computing $R$ [9].

A series of GNSS-based position observables was artificially created in $\mathrm{R}$, using the algorithm defined in Equation 15.

$$
\left(\varphi_{1}=\varphi_{0}+i \cdot 10^{-6}, \lambda_{i}=\lambda_{0}+i \cdot 10^{-6}\right), i=1, \ldots, 200
$$

The series of position estimates with coordinates in the spherical reference frame 15 was translated into a series of position estimates with Cartesian coordinates using 7-9. The coordinates of the reference point $\left(\varphi_{0}, \lambda_{0}\right)$ were translated into Cartesian coordinates $\left(x_{0}, y_{0}\right)$.

The algorithm 12-14 was applied to the series of observables in spherical coordinates 15 to determine the distance from the reference point $\left(\varphi_{0}, \lambda_{0}\right)$. This procedure generated a series of haversine distance estimates, dh, expressing position errors as distances between two points on a sphere representing the Earth.

The method 1 was applied to the series of observables in Cartesian framework to determine the distance from the reference point $\left(x_{0}, y_{0}\right)$. This procedure generated a series of Cartesian distance estimates, d C, expressing position errors as distances between two points in the 3D space, without reference to any object or shape.

Two series of distances were compared for their absolute values (Figure 3), absolute distance calculation errors with d $\mathrm{C}$ series as a reference (Figure 4), and relative distance calculation errors with $\mathrm{d} C$ series as a reference (Figure 5). Absolute distance is defined as the Euclidian distance in 3D space. Relative distance is determined in relative terms, as the ratio of absolute distance error over true distance.

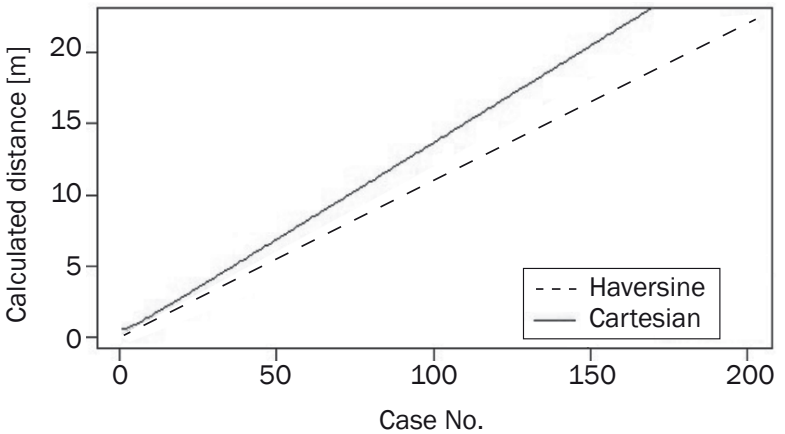

Figure 3 - Calculated distance using Cartesian and haversine algorithms

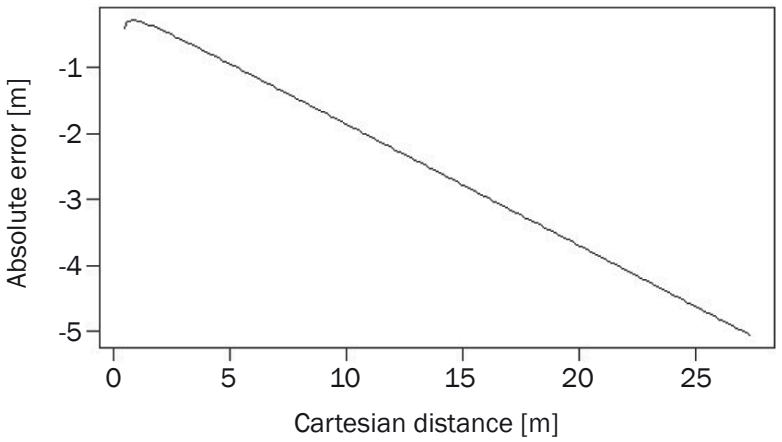

Figure 4 - Absolute distance calculation error, with Cartesian values used as the reference

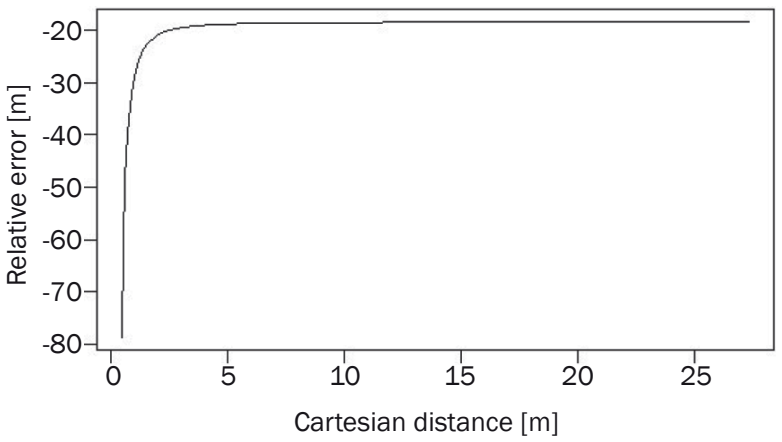

Figure 5 - Relative distance calculation error, with Cartesian values used as the reference

\section{DISCUSSION}

Two most commonly used methodologies for determination of GNSS positioning accuracy based on raw GNSS observables were presented. The results of a simulation (Figure 3) show different behavior of the Cartesian and the haversine approaches. With the Cartesian approach used as a reference, the performance of the haversine approach was evaluated in both absolute and relative terms. As the Cartesian values were considered true, the absolute error caused by the implementation of the haversine approach is mostly proportional to the actual distance to be presented (Figure 4). Considering the relative terms (Figure 5), the 
haversine approach shows poor performance at small distances, while stabilizing to the value of approximately $20 \%$ for larger actual distances.

Reducing the domain to navigation applications (which includes location-based services and intelligent transport systems) used by non-stationary objects, the haversine approach still performs relatively poorly. Finally, the initial calculation of a GNSS position estimate is conducted in a GNSS receiver using the Cartesian reference system, making it a more natural solution for determination of GNSS position accuracy.

The haversine formula method reduces the inaccuracy in positioning error estimation caused by incorrect simplifications in the process. However, the mitigation effects of the haversine formula are of limited scope. This finding led to a recommendation for utilization of WGS84-expressed coordinates of position estimates, taken from dedicated APIs of GNSS SDR receivers, for studying GNSS positioning performance in LBS and ITS application scenarios.

\section{CONCLUSION}

Frequent encounters with miscalculated values of GNSS positioning errors derived from true and observed positions motivated this study. We identified a problem in false assumption of identity between position coordinates in geographical and 3D Cartesian reference systems that is further utilized in position error estimation based on positions expressed in the geographical reference system, a common practice in traditional low-cost receiver design. We challenged the problem by introducing the haversine formula, a method for transformation from the geographical to the Cartesian 3D reference system (WGS84 in case of GNSS utilization). We then examined the performance of position error estimation and identified the potential scenarios where the haversine formula approach may improve the accuracy of position estimation and reduce the effects of reference frame transformation. However, our study shows that the haversine formula approach cannot be generalized in targeted categories of applications (location-based services and intelligent transport systems). This finding led to the recommendation of utilization of directly accessible WGS84-expressed position in studying GNSS positioning performance in LBS and ITS, which overcomes the effects of reference frame transformation. Increasing the utilization of GNSS software-defined radio architectures and recent developments in rendering GNSS position estimates through dedicated application programming interfaces (APIs) supports the recommendation of our study.

MIA FILIĆ, mag.inf. et math. ${ }^{1}$

E-mail: filicmia@gmail.com

Prof. dr. sc. RENATO FILJAR ${ }^{2}$

E-mail: renato.filjar@gmail.com

Doc. dr. SC. MARKO ŠEVROVIć 3

E-mail: msevrovic@fpz.hr
${ }^{1}$ Sveučilište u Zagrebu Fakultet elektrotehnike

i računarstva, Unska 3, 10000 Zagreb, Hrvatska

2 Sveučilište u Rijeci, Tehnički fakultet

Vukovarska 58, 51000 Rijeka, Hrvatska

${ }^{3}$ Sveučilište u Zagrebu, Fakultet prometnih znanosti

Vukelićeva 4, 10000 Zagreb, Hrvatska

\section{IZRAŽAVANJE POZICIJSKIH POGREŠAKA U GNSS SUSTAVU POMOĆU UDALJENOSTI}

\section{SAŽETAK}

$U$ radu se analiziraju dvije metode određivanja pozicijskih pogrešaka u globalnom navigacijskom satelitskom sustavu (eng. Global Navigation Satellite System - GNSS). Analizirane metode služe za procjenu uspješnosti određivanja položaja, a zasnivaju se na izračunu razlika između mjerenog i stvarnog položaja. Jedna metoda koristi Kartezijev 3D koordinatni sustav, a druga sferni koordinatni sustav. Za određivanje udaljenosti koristi se metoda udaljenosti u Kartezijevom referentnom sustavu te "haversine" formule (formula polovine sinus versusa). Istraživanje ukazuje na neriješene probleme u procjeni performansi GNSS određivanja položaja pri uporabi procjene položaja u geografskom referentnom sustavu. Zbog spomenutih problema za procjenu uspješnosti određivanja položaja preporuča se korištenje postupaka procjena pogreške položaja zasnovanih na originalnom WGS84 standardu, primijenjenim u programski određenim radio prijamnicima (SDR).

\section{KLUUČNE RIJEČI}

pogreške određivanja položaja GNSS-om; procjena učinka; izračun udaljenosti; programski određen radio prijemnik $(\mathrm{SDR})$;

\section{REFERENCES}

[1] Petrovski I, Tsujii T. Digital Satellite Navigation and Geophysics: A Practical Guide with GNSS Signal Simulator and Receiver Laboratory. Cambridge, UK: Cambridge University Press; 2012.

[2] EUROCONTROL, IfEN. WGS 84 Implementation Manual. Bruxelles, Belgium: Eurocontrol, Munich, Germany: Institute of Geodesy and Navigation (IfEN), University FAF; 1998. Available from: http://bit.ly/2cvJHc4 [Accessed January 29, 2018].

[3] Filjar R, Desic S, Huljenic D. Satellite Positioning for LBS: A Zagreb Field Positioning Performance Study. The Journal of Navigation. 2004;57(3): 441-447. Available from: doi:10.1017/S0373463304002851 [Accessed January 29, 2018].

[4] Oxley A. Uncertainties in GPS Positioning: A mathematical discourse. London, UK: Academic Press/Elsevier; 2017.

[5] Sinott R W. Virtues of true position. Sky and Telescope. 1984;68: 159.

[6] Filić M, Filjar R, Ruotsalainen L. An SDR-based Study of Multi-GNSS Positioning Performance During Fast-developing Space Weather Storm. TransNav. 2016;10: 395400. Available from: doi:10.12716/1001.10.03.03, http://bit.ly/2fxAvph [Accessed on January 29, 2018].

[7] GNSS Raw Measurements Task Force. Using GNSS 
Raw Measurements on Android Devices. Prague, Czechia: European Global Navigation Satellite Systems Agency. Available from: http://bit.ly/2jaddWU [Accessed on January 29, 2018].

[8] Vincenty T. Direct and inverse solutions of geodesics on the ellipsoid with application of nested equations.
Survey Review. 1975;XXII(176): 88-93.

[9] R Development Core Team. R: A language and environment for statistical computing. Vienna, Austria: $\mathrm{R}$ Foundation for Statistical Computing; 2011. Available from: http://www.R-project.org/ [Accessed on January 29,2018$]$. 